sciendo

\title{
Será o Contratualismo Reconciliável com o Consequencialismo?
}

\author{
Pedro Galvão \\ University of Lisbon
}

Disputatio Vol. 4, No. 34

December 2012

DOI: $10.2478 /$ disp-2012-0024

ISSN: 0873-626X 


\title{
Será o Contratualismo Reconciliável com o Consequencialismo?
}

\author{
Pedro Galvão \\ Universidade de Lisboa e Grupo LanCog \\ BIBLID [0873-626X (2012) 34; pp. 625-634]
}

Será que o contratualismo e o consequencialismo poderão convergir na prática? Admitir que sim é julgar que estas perspectivas, apesar de oferecerem fundamentos diferentes para a obrigação moral, poderão implicar exactamente o mesmo quanto à permissividade de todo e qualquer acto, de tal forma que os actos permissíveis de acordo com um contratualista serão permissíveis de acordo com um consequencialista, sendo o mesmo verdade a respeito dos actos impermissíveis.

Este tipo de convergência, vou sustentar, só poderá verificar-se entre versões indefensáveis de contratualismo ou de consequencialismo. Portanto, se alguém argumentar que uma certa perspectiva contratualista converge com uma certa perspectiva consequencialista, teremos de dizer o seguinte: não há realmente convergência entre essas perspectivas ou, se há, pelo menos uma delas será indefensável, o que torna a convergência desinteressante.

$\mathrm{O}$ meu argumento contra a possibilidade de uma convergência interessante entre o contratualismo e o consequencialismo baseiase numa questão acerca da qual vários contratualistas têm divergido efectivamente de vários consequencialistas: a questão das nossas obrigações para com os animais não-humanos. (Por uma questão de concisão, usarei simplesmente o termo «animais» para me referir aos animais das outras espécies.) Vou defender que esta divergência é insanável, argumentando a favor das seguintes teses:

1. Qualquer consequencialismo defensável implica que alguns animais têm estatuto moral. 
2. Qualquer contratualismo defensável implica que nenhum animal tem estatuto moral.

Nas próximas duas secções justificarei, respectivamente, 1 e 2. Destas teses segue-se que nenhum consequencialismo defensável converge com um contratualismo defensável.

Afirmar que há animais com estatuto moral, importa esclarecer desde já, é dizer que temos obrigações para com alguns animais. Por outras palavras, é pensar que temos deveres directos em relação a alguns animais. Se temos estes deveres, um deles será seguramente o de não infligir dor ou sofrimento a animais - concebido apenas como um dever prima facie, note-se. Quem considera que este dever é directo entende que não devemos fazer sofrer animais porque o sofrimento é mau para eles, vai contra os seus interesses, e não simplesmente porque infligir-lhes sofrimento seja mau, de alguma forma, para os seres humanos ou vá contra os nossos interesses. O consequencialista não poderá deixar de aceitar um dever como este; o contratualista, pelo contrário, não poderá admiti-lo.

John C. Harsanyi, embora nunca se tivesse descrito como «contratualista», conta-se entre os autores que argumentaram a favor de uma convergência do contratualismo com o consequencialismo. A última secção deste artigo centra-se no argumento de Harsanyi. Inspeccionando-o, veremos melhor como o esforço de reconciliação parece condenado ao fracasso.

Podemos seriar estados de coisas alternativos segundo o seu valor impessoal, adoptando um ponto de vista estritamente imparcial e maximamente abrangente. Directa ou indirectamente, o consequencialista baseia a sua atribuição de permissividade a actos neste tipo de seriação de estados de coisas. No primeiro caso será um consequencialista de actos, sendo de esperar que defenda o seguinte:

Um acto é permissível se e somente se não há um acto alternativo que resultasse num estado de coisas melhor.

Se optar antes por uma abordagem indirecta, poderá ser um consequencialista de regras e sustentar o seguinte: 
Um acto é permissível se e somente se está em conformidade com um código moral óptimo.

Um código moral é óptimo se e somente se não há um código moral alternativo que resultasse num estado de coisas melhor (se colhesse a aceitação geral).

Há outras versões de consequencialismo, tanto directas como indirectas, mas na presente discussão aquilo que as distingue entre si não é importante.

Alguns consequencialistas são hedonistas. Pensam que só o prazer é intrínseca e fundamentalmente bom, e que só o sofrimento é intrínseca e fundamentalmente mau. Para estes consequencialistas, dados quaisquer dois estados de coisas alternativos, o melhor será sempre aquele em que houver mais prazer, descontado o sofrimento.

O hedonismo é seguramente uma perspectiva muito controversa e bastante impopular nos tempos que correm. Muitos consequencialistas - a maioria, na verdade — recusar-se-iam a seriar estados de coisas unicamente segundo o critério do «saldo hedónico». Defenderiam que outros critérios - por exemplo, o exercício da autonomia, a satisfação de desejos, a compensação pelo mérito, a igualdade na distribuição do bem-estar ou a integridade dos ecossistemas — são importantes para efectuar as seriações. Como esta lista permite entrever, há muitas questões interessantes a discutir quanto ao modo correcto de avaliar estados de coisas em termos do seu valor impessoal. Mas saber se o sofrimento será um dos factores importantes a atender nesse tipo de avaliação não é uma dessas questões. Qualquer consequencialista razoável, por maior que seja a sua aversão ao hedonismo, aceitará o seguinte: ceteris paribus, um estado de coisas é melhor do que outro se nele houver menos sofrimento - ou, talvez, menos sofrimento imerecido. Uma perspectiva consequencialista em que os estados de coisas fossem seriados sem se atribuir um peso negativo considerável ao sofrimento resultaria em conclusões práticas extremamente contra-intuitivas, para dizer o mínimo.

Ora, nem só os seres humanos têm a capacidade de sofrer. Ainda que só os membros da nossa espécie estejam sujeitos a certas formas particularmente intensas de sofrimento, partilhamos com muitos outros animais capacidades semelhantes para experienciar dor física, bem como para ter sentimentos de angústia, medo e tédio. De um 
ponto de vista estritamente imparcial e maximamente abrangente, o sofrimento dos animais não só não pode ser ignorado como deve ter a mesma importância que o sofrimento semelhante dos seres humanos. Avaliar estados de coisas sem atender ao sofrimento dos membros das outras espécies seria tão arbitrário como fazê-lo sem considerar, por exemplo, o sofrimento dos seres humanos de algumas raças ou de um dos sexos. ${ }^{1}$

Admitamos, então, que o consequencialista tem de basear a sua perspectiva numa concepção do valor em que o sofrimento dos animais conte como algo intrinsecamente mau ou desvalioso. Se ele for um consequencialista de actos, incluirá esse sofrimento entre as consequências dos actos que contribuem invariavelmente - ainda que nem sempre de forma decisiva - para os tornar errados. E, se ele for antes um consequencialista de regras, também admitirá um dever prima facie de não maltratar animais, já que a aceitação geral de um código moral que sancione este dever teria seguramente melhores consequências do que a aceitação geral de um código moral que consentisse a indiferença total em relação ao bem-estar dos animais.

Qualquer consequencialista, portanto, deverá aprovar uma preocupação directa com os animais, tomando sempre o facto de um acto resultar em sofrimento para um animal como uma razão para não o realizar. Não é assim de estranhar que, de Bentham a Singer, os representantes mais destacados da tradição consequencialista tenham figurado entre os defensores de uma maior consideração pelos interesses dos animais. À luz de qualquer versão defensável de consequencialismo, práticas como a criação intensiva de animais, ou o seu uso em laboratórios para fins triviais, deverão ser abolidas em virtude de envolverem uma enorme desproporção entre os males infligidos aos animais e os benefícios que os seres humanos obtêm.

Examinemos agora a perspectiva contratualista, que admite a seguinte formulação concisa:

\footnotetext{
${ }^{1}$ Peter Singer, na sua célebre crítica ao «especismo», defendeu pormenorizadamente que a discriminação baseada na espécie é análoga às discriminações baseadas na raça ou no sexo. Veja-se Singer 1974.
} 
Um acto é permissível se e somente se está em conformidade com os princípios que os agentes racionais acordariam entre si para governarem a sua interacção.

Os contratualistas baseiam a ética num acordo hipotético, realizado em circunstâncias ideais, mediante o qual os agentes racionais definem os termos da sua coexistência em sociedade. Ora, os animais, mesmo os mais inteligentes, são manifestamente incapazes de participar num acordo - e muito menos num acordo desta natureza, centrado na escolha de princípios morais. Deste modo, parece que as partes contratantes não terão razões para aceitar um código moral em que os interesses dos animais sejam considerados directamente. Peter Carruthers (1992), o contratualista que melhor explorou esta questão, defendeu isto mesmo: que o contratualismo não deixa espaço para a atribuição de estatuto moral aos animais. Os animais, em seu entender, importam apenas indirectamente de um ponto de vista ético. Não devemos tratá-los de certas formas, mas isso apenas devido aos direitos e aos interesses dos seres humanos. Por exemplo, matar certos animais será errado em virtude de violar os direitos dos seus proprietários, e maltratar animais em público poderá ser errado em virtude de ferir a sensibilidade de algumas pessoas.

Há dois tipos principais de contratualismo, que diferem na concepção das circunstâncias ideais do contrato ético. ${ }^{2}$ No contratualismo rawlsiano, os agentes desconhecem as suas características e interesses pessoais. Têm conhecimento de factos gerais de natureza psicológica e sociológica, mas, como estão sob um véu de ignorância, ignoram o seu sexo, raça, classe social, bem como os seus talentos naturais e os seus projectos individuais. Por isso, os agentes efectuarão a sua escolha de princípios desconhecendo o lugar que irão ocupar na sociedade (Rawls 1971). No contratualismo scanloniano, pelo contrário, não há qualquer véu de ignorância. Todos os agentes conhecem a sua posição na sociedade e as suas características pessoais. Contudo, partilham o objectivo de encontrar princípios que «ninguém possa rejeitar razoavelmente enquanto base para um acordo geral, livre e informado» (Scanlon 1998: 153).

Consideremos o contratualismo rawlsiano. Dado que os agentes,

${ }^{2}$ Ignoro aqui o contratualismo hobbesiano, cuja incompatibilidade com a atribuição de estatuto moral aos animais é perfeitamente evidente. 
sob o véu de ignorância, ignoram a sua raça e o seu sexo, não escolherão princípios que neguem estatuto moral aos seres humanos de algumas raças ou de um dos sexos. Mas, por muito espesso que seja esse véu, os agentes saberão que não se incluem entre os animais, dado que estes são incapazes de participar numa escolha de princípios morais. Deste modo, não admitirão quaisquer obrigações para com os membros das outras espécies.

Uma forma de resistir a este resultado consiste em introduzir a suposição de que, entre as partes contratantes, figuram agentes racionais cuja função é representar os animais e defender os seus interesses. Muito plausivelmente, a participação desses agentes no contrato ético resultaria na escolha de princípios que concedessem estatuto moral aos animais. Esta versão de contratualismo rawlsiano, no entanto, é indefensável: a suposição indicada, sendo destituída de uma justificação independente e servindo apenas conferir estatuto moral aos animais, é puramente ad hoc (Carruthers 1992: 99-100).

O contratualismo scanloniano é igualmente adverso à perspectiva de que os animais têm estatuto moral. É verdade, sem dúvida, que muitos dos agentes racionais envolvidos no contrato poderão importar-se com os animais, ter uma preocupação com o seu bem-estar. Mas esta preocupação, como sustenta Carruthers, não oferece uma razão adequada para rejeitar um código moral sem obrigações para com os animais:

[N]ão será razoável uma pessoa rejeitar uma regra se outras pessoas teriam um fundamento igual para rejeitar qualquer regra proposta. Pois, nesse caso, não conseguiríamos atingir o nosso objectivo partilhado de chegar a um acordo geral, livre e sem coacção. Não poderá ser razoável, portanto, rejeitar uma regra simplesmente por esta estar em conflito com um dos meus interesses ou preocupações. Pois qualquer regra (se não for completamente trivial) estará em conflito com as preocupações de alguém. Talvez eu me importe profundamente com o bem-estar dos animais. Mas outros preocupam-se profundamente com padrões de vestuário e aparência, modos de actividade sexual e a adoração do seu deus. Se eu puder rejeitar razoavelmente regras que não atribuem qualquer peso aos interesses dos animais, outros poderão rejeitar de forma igualmente razoável regras que nos permitam vestir e fazer amor como desejarmos, e adorar ou não adorar como bem entendermos. (1992: 104)

Para nos restringirmos ao tema em discussão, suponhamos que o contrato ético envolve, além de agentes que se preocupam com bem 
- estar dos animais, agentes que se preocupam de forma igualmente intensa com a manutenção de actividades incompatíveis com a atribuição de estatuto moral aos animais. Numa versão de contratualismo scanloniano em que se considerasse que os primeiros, apelando à sua preocupação, poderiam rejeitar razoavelmente princípios que negassem estatuto moral aos animais, teríamos de admitir que os segundos, apelando à sua preocupação, também poderiam rejeitar razoavelmente princípios que atribuíssem estatuto moral aos animais. $\mathrm{E}$ assim, a respeito do tratamento dos animais, não haveria quaisquer princípios que não pudessem ser razoavelmente rejeitados. Esta versão de contratualismo, portanto, seria indefensável: não permitiria que as partes contratantes chegassem alguma vez a um acordo. Sob a perspectiva scanloniana, o facto de algumas pessoas se importarem com bem-estar dos animais não poderá contar como uma razão para escolher princípios que lhes confiram estatuto moral.

Em suma, ao passo que os agentes rawlsianos serão indiferentes aos interesses dos animais, os agentes scanlonianos, ainda que possam importar-se com esses interesses, não poderão apelar à sua preocupação para rejeitar um código moral que os ignore. Num enquadramento contratualista, a perspectiva de que os animais têm estatuto moral não encontra o menor apoio. À luz de qualquer versão defensável de contratualismo, como Carruthers (1992: 107-108, 159-160) sublinha, não há razões para reprovar práticas como a criação intensiva de animais ou o seu uso em laboratórios, mesmo para fins triviais.

John Harsanyi defendeu uma ética consequencialista, mais precisamente um utilitarismo de média: grosso modo, a perspectiva de que os princípios morais correctos são aqueles cuja adopção maximizaria o bem-estar médio. O seu argumento principal a favor desta perspectiva, embora tenha precedido a teoria da justiça de Rawls, é facilmente enquadrável no contratualismo rawlsiano. ${ }^{3}$ Pois Harsanyi, à semelhança de Rawls, alega que os princípios correctos são aqueles que os agentes racionais escolheriam se estivessem sob um véu de igno-

${ }^{3}$ Harsanyi apresentou este argumento em várias ocasiões. Mas veja-se sobretudo Harsanyi 1977. 
rância, desconhecendo a posição que irão ocupar no mundo em que os princípios serão implementados. Porém, enquanto Rawls sustenta que os agentes repudiariam princípios utilitaristas, Harsanyi defende o contrário, sugerindo assim uma convergência entre o consequencialismo e o contratualismo - um contratualismo diferente do de Rawls, mas que, em virtude do recurso ao véu de ignorância, não deixa de ser rawlsiano.

O desacordo entre Rawls e Harsanyi respeita sobretudo ao procedimento de escolha apropriado para os agentes racionais. Rawls advoga o maximin, um procedimento de escolha extremamente prudente que se deixa traduzir na seguinte perspectiva: os agentes deverão avaliar os princípios como se tivessem a certeza de que vão ficar na posição de um dos indivíduos mais desfavorecidos. Harsanyi sugere antes que os agentes deverão efectuar essa avaliação supondo que a probabilidade de ficarem em cada uma das posições possíveis é rigorosamente a mesma. Ora, estando motivados pelo interesse pessoal, os agentes escolherão assim os princípios que resultem num maior bem-estar médio — em detrimento, por exemplo, dos princípios que resultem num maior bem-estar para os mais desfavorecidos. ${ }^{4}$ Deste modo, um contratualismo rawlsiano gera uma perspectiva consequencialista.

Importa agora perguntar se o consequencialismo resultante será defensável. E a resposta, pelas razões indicadas, tem de ser negativa. Dado que os agentes rawlsianos sabem que em caso algum ficarão na posição de um animal, irão ignorar o bem-estar dos animais ao seleccionar os princípios que governarão a sua interacção. Escolherão assim os princípios, se adoptarem o procedimento de escolha que Harsanyi recomenda, cuja adopção resulte num maior bem-estar médio para os seres humanos, ${ }^{5}$ deixando de fora o bem-estar dos membros de todas as outras espécie. Mas, como vimos, de uma perspectiva consequencialista é arbitrário excluir os interesses dos animais. Portanto, o argumento rawlsiano de Harsanyi conduz a uma versão indefensável de consequencialismo.

${ }^{4}$ Para uma apresentação mais pormenorizada do argumento, veja-se Galvão 2007: 100-102.

${ }^{5} \mathrm{Ou}$, pior ainda, talvez apenas para alguns seres humanos, já que nem todos os membros da nossa espécie são agentes racionais. 
É verdade que podemos tentar remediar esta falha do argumento. Para que os princípios escolhidos pelos agentes racionais sejam aqueles cuja adopção resultasse num maior bem-estar médio verdadeiramente geral, podemos redescrever apropriadamente as circunstâncias ideais em que esses agentes efectuam a escolha. Uma possibilidade, que sugeri noutra ocasião (Galvão 2007: 111-112), consiste em tornar o véu de ignorância um pouco mais espesso, introduzindo uma «Condição de amnésia»: antes de efectuarem a escolha, os agentes ficam privados do conhecimento da identidade de todos aqueles cujo bem-estar será afectado. Inicialmente, os agentes poderão saber (1) quem são todos os indivíduos afectados - incluindo os animais - e (2) que nível de bem-estar cada indivíduo obterá se os diversos princípios em consideração forem adoptados. Antes de escolherem os princípios, no entanto, os agentes «esquecem» 1 , ainda que retenham a informação correspondente a 2. Desta forma, deixam de saber se os indivíduos em questão são animais ou humanos, mas saberão em que medida o seu bem-estar será afectado com a adopção de cada conjunto de princípios. E assim efectuarão a escolha como se pudessem vir a ocupar a posição dos animais, o que os levará a preferir os princípios cuja adopção resulte no maior bem-estar médio, considerados todos os seres sencientes.

Esta nova versão de contratualismo rawlsiano tem, portanto, a vantagem de conduzir a um consequencialismo que não deixa de fora os interesses dos animais - e que por isso seria indefensável. Contudo, a «condição da amnésia» afigura-se puramente ad hoc, pelo torna indefensável qualquer perspectiva que a inclua.

Em suma, o argumento inicial de Harsanyi gera um consequencialismo indefensável. Ao repararmos a sua falha, acabamos com um contratualismo indefensável. Depois da discussão realizada nas duas secções anteriores, este resultado não deve surpreender-nos: se qualquer consequencialismo defensável diverge de qualquer contratualismo defensável no que respeita ao estatuto moral dos animais, a convergência entre estas posições só se realiza quando pelo menos uma delas se apresenta numa versão manifestamente indefensável. Se o argumento aqui apresentado é sólido, a questão de saber se haveremos de ser consequencialistas ou contratualistas mantém, pois, uma 
importância prática muito significativa. ${ }^{6}$

Pedro Galvão Universidade de Lisboa e Grupo LanCog

\section{Referências}

Carruthers, Peter. 1992. The Animals Issue: Moral Theory in Practice. Cambridge: Cambridge University Press.

Galvão, Pedro. 2007. Do Ponto de Vista do Universo: Um Estudo sobre a Racionalidade da Ética Consequencialista. Lisboa: Centro de Filosofia da Universidade de Lisboa.

Harsanyi, John C. 1977. Morality and the Theory of Rational Behaviour. In A. Sen e B. Williams. Utilitarianism and Beyond. Cambridge: Cambridge University Press, 1982, 39-62.

Rawls, John. 1971. A Theory of Justice. Cambridge: Harvard University Press.

Scanlon, T. M. 1998. What We Owe to Each Other. Cambridge: Harvard University Press.

Singer, Peter. 1974. All Animals Are Equal. Philosophical Exchange, 1: 103-116.

${ }^{6}$ Através de uma Bolsa de Pós-Doutoramento (SFRH/BPD/27852/ 2006), beneficiei, na realização deste trabalho, do apoio da Fundação para a Ciência e a Tecnologia no âmbito do III Quadro Comunitário de Apoio.

Este artigo não obedece ao Acordo Ortográfico de 1990. 